\title{
Kinetics of serum amyloid A during the treatment period of foals with pneumonia
}

\author{
Anna Lankenfeld', Corinna Weber2, Karl Rohn ${ }^{3}$ and Monica Venner ${ }^{4}$ \\ 1 Equine Clinic, University of Veterinary Medicine Hanover, Hanover, Germany \\ 2 LABOKLIN GmbH\&Co.KG, Bad Kissingen, Germany \\ 3 Department of Biometry and Epidemiology, University of Veterinary Medicine Hanover, Hanover, Germany \\ ${ }^{4}$ Equine Clinic Destedt, Germany
}

\begin{abstract}
Summary: The ultrasonographic examination of foals with pneumonia has been proven successful in monitoring the course of the disease during treatment. However, the question arises whether another parameter, such as the acute phase protein serum amyloid A (SAA), could also be suitable for evaluating the response to treatment, the course during treatment or the decision to terminate the treatment in foals with pneumonia. The course of moderate or severe pneumonia was recorded by several diagnostic tests in a prospective study performed on 52 foals. Clinical and ultrasonographical examination of the thorax and blood values (SAA, white blood cell count) of these foals were measured on the day of diagnosis and weekly during treatment. Foals with a pulmonary abscess score of $15-19.5 \mathrm{~cm}$ determined by sonography of the thorax (moderate pneumonia) were assigned to group $1(n=31)$ and received a treatment with rifampin and tulathromycin. If the abscess score was $>20 \mathrm{~cm}$ (severe pneumonia), the foals were included in group $2(\mathrm{n}=21)$ and were treated with rifampin and azithromycin. All foals recovered during the treatment period. Sonography of the thorax of the foals with moderate pneumonia (group 1) showed no more pathologic findings after ten days, and the foals with severe pneumonia (group 2) after eleven days of treatment. At diagnosis the median SAA value at diagnosis was $367 \mathrm{mg} / \mathrm{L}$ (median; 25th/75th: 23-937) in foals with moderate pneumonia and 216 mg/L (median; 25th/75th: 16-690) in those with severe pneumonia. The SAA values of foals with initially elevated values decreased significantly until they reached normal values $<40 \mathrm{mg} / \mathrm{L}$ after five days in the foals with moderate pneumonia and four days in the those with severe pneumonia. The time between the day SAA reached normal values and ultrasonography of the lung revealed no more abnormalities was three days in foals with moderate pneumonia and seven days in those with severe pneumonia. The SAA as a diagnostic method had a sensitivity of $68 \%$ in the case of moderate pneumonia and $71 \%$ in the case of severe pneumonia on the day of diagnosis. If only the foals with pneumonia and fever were considered, $91 \%$ showed an initially increased SAA. During treatment, the SAA correlated with the abscess score, the clinical score and the age at diagnosis, but not with the number of white blood cells. In conclusion, the ultrasonographic examination remains the most precise tool to diagnose pneumonia and follow its progress during treatment in foals. However, the SAA can be used as an additional parameter for evaluating the treatment success. Especially foals with fever and younger foals show high SAA values in patients with pneumonia. By observing the kinetics of SAA in a patient, this blood parameter could be a support to adjust the date of the final ultrasonographic examination. Thereby, the duration of treatment can be individually adapted.
\end{abstract}

Keywords: foal, pneumonia, serum amyloid A, treatment period, ultrasound examination

Citation: Lankenfeld A., Weber C., Rohn K., Venner M. (2021) Kinetics of serum amyloid A during the treatment period of foals with pneumonia. Pferdeheilkunde 37, 128-137; DOI 10.21836/PEM20210204

Correspondence: PD Dr. Monica Venner PhD, Equine Clinic, Trift 4, 38162 Destedt, Germany; mvenner@gmx.de

Received: December 3, 2020 | Accepted: December 17, 2020

\section{Introduction}

Pneumonia is a frequent and common disease in foals on equine breeding farms. A common cause of abscessing bronchopneumonia in foals up to the age of six months is infection with Rhodococcus equi (R. equi) (Giguère and Prescott 1997). However, other pathogens, such as Streptococcus ssp., Klebsiella pneumoniae, Actinobacillus spp. and Escherichia coli, should be considered as the symptoms and diagnostic imaging methods reveal similar findings (Hoffmann et al. 1993, Lavoie et al. 1994). Screening programmes are recommended to detect affected foals as early as possible as diagnosis can be difficult due to the initially subclinical course of abscessing pneumonia. Early diagnosis is associated with reduced fatalities and short- er treatment duration (Cohen et al. 2005, Giguère et al. 2011 a). The most reliable diagnostic tool to detect pneumonia in foals is the sonographic examination of the lung (Slovis et al. 2005). Clinical examination and haematology, especially blood leukocyte (white blood cells: WBC) counts or fibrinogen are less sensitive compared to sonography (Giguère et al. 2003).

A further blood parameter, the acute phase protein (APP) serum amyloid $A(S A A)$, could be useful in the diagnosis of pneumonia in foals due to its rapid response as an inflammatory marker. The SAA is one of the positive reacting major APPs in horses and indicates inflammatory reactions and tissue damage in the body with a marked increase of up to hundredfold within 6-12h, with peak values expected 
after approximately $48 \mathrm{~h}$ in horses (Jacobsen and Andersen 2007).

On the one hand, SAA is mentioned as a useful parameter, together with the clinical status of the foal, to detect pneumonia early in the context of monitoring programmes (Hultén et al. 2002, Belgrave et al. 2013). On the other hand, SAA has only been given a moderate value as a diagnostic tool for pneumonia in foals: its sensitivity (77 and 64\%, respectively) and specificity (80 and $77 \%$, respectively) were too low in two recent studies (Giguère et al. 2016, Thomé et al. 2018) to use the SAA reliably to diagnose pneumonia in foals, however, it can be quite helpful due to its sensitive and fast reaction.

Another nearly similarly reacting APP, the C-reactive protein (CRP), was used successfully in dogs in a recent study as a parameter to determine the duration of bacterial bronchopneumonia treatment needed individually (Viitanen et al. 2017). The SAA and CRP plasma concentrations begin to decrease shortly after the completion of synthesis due to their short halflives. These properties make those major APPs well-suited for the real-time monitoring of acute inflammation (Jacobsen and Andersen 2007, Prato et al. 2012), whereby SAA seems to be even more sensitive in horses than CRP, which is a minor APP in horses (Heyers 2005). There is a need to assess the pulmonary changes during the treatment of a foal with pneumonia and make a decision for a change or the end of treatment. Therefore, it might be useful to investigate parameters that provide information about the inflammatory situation and the tissue damage in the body.

The aim of the study was to evaluate the kinetics of SAA during the treatment of pneumonia in foals. Additionally, the course of SAA was compared to the ultrasonographic findings in order to see whether SAA is a useful parameter to assess the individual duration of treatment for pulmonary disorders.

\section{Material and methods}

A total of 52 foals of a breeding farm were included in the study during the breeding season in 2018. The stud has had endemic pneumonia due to R. equi in foals for several years; the pathogen has been repeatedly isolated in different years and studies (Venner et al. 2007, Lämmer 2010, Hagist 2016). In addition, R. equi was isolated from foals with pneumonia in a further study at the same farm in the breeding season in the same year (Hennig 2020 in print).

All foals at the stud from the age of one to six months were submitted to a screening protocol to detect affected foals early. This procedure included a clinical examination with measurement of the body temperature, evaluation of the mandibular lymph nodes and the nasal discharge, and auscultation of the trachea and lungs. The findings were added to a clinical score (Table 1). Furthermore, the WBC were counted and an ultrasonographic examination of the chest was performed as the reference method for the detection of pneumonia. Thoracic ultrasound was done using portable equipment with a $7.5 \mathrm{MHz}$ linear transducer, with the hair coat wetted with alcohol instead of shaving. An abscess was defined as a hypo- or anechoic area of consolidation interrupting the hyperechoic line of the well ventilated lung. After examination of both sides of the chest, all consolidations detected with a diameter $\geq 0.5 \mathrm{~cm}$ were added to a total abscess score in $\mathrm{cm}$.

If a moderate or a severe abscessing bronchopneumonia was diagnosed, the foal had no signs of dyspnoea and was four weeks of age or older, it was included in the study. The foals with an abscess score from $15-19.5 \mathrm{~cm}$ were assigned to group 1 (moderate pneumonia) of this study $(n=31)$ and were treated with rifampin $(10 \mathrm{mg} / \mathrm{kg} P O, \mathrm{q} 24 \mathrm{~h})$ and tulathromycin $(2.5 \mathrm{mg} / \mathrm{kg} \mathrm{IM}, \mathrm{q} 7$ days $)$. Foals with an abscess score of $20 \mathrm{~cm}$ or higher were assigned to group 2 (severe pneumonia) of this study $(n=21)$ and a treatment with rifampin $(10 \mathrm{mg} /$ $\mathrm{kg} \mathrm{PO}, \mathrm{q} 24 \mathrm{~h}$ ) and azithromycin (10 mg/kg PO, q $24 \mathrm{~h})$ was started. The clinical score was recorded once a week during treatment and ultrasonographic examination and blood sampling (WBC count and SAA) were done twice weekly.

When the blood in the serum tubes was clotted, it was centrifugated for $10 \mathrm{~min}$, then the serum was pipetted into Eppendorf tubes and was stored at $-18^{\circ} \mathrm{C}$ for the later analysis of SAA. Upon completion of the study, an external laboratory (LABOKLIN $\mathrm{GmbH} \& \mathrm{Co}$. KG, Bad Kissingen, Germany) analysed the serum samples for SAA using an automated latex agglutination test. Concentrations of SAA $>40 \mathrm{mg} / \mathrm{L}$ were considered as an indication of an inflammatory disorder. In a previous study, healthy foals no older than 12 months were sampled and an SAA of $21.2 \mathrm{mg} / \mathrm{L}( \pm 12.2)$ was found, which supports the definition of this reference range (Satué et al. 2013).

\section{Data Analysis}

The Statistical Analysis System for Windows SAS ${ }^{\circledR}$, Version 9.4, using the SAS ${ }^{\circledR}$ Enterprise Guide ${ }^{\circledR}$ Version 7.1 Client, was

\begin{tabular}{|c|c|c|}
\hline Table 1 & Klinischer Score. & \\
\hline Characteristic & Findings & Score \\
\hline \multirow{3}{*}{ nasal discharge } & normal & 0 \\
\hline & serous & 1 \\
\hline & mucous, purulent & 2 \\
\hline \multirow{3}{*}{$\begin{array}{l}\text { body tempera- } \\
\text { ture }\end{array}$} & normal $\left(\leq 38.9^{\circ} \mathrm{C}\right)$ & 0 \\
\hline & mildly elevated $\left(39.0-39.4^{\circ} \mathrm{C}\right)$ & 1 \\
\hline & highly elevated $\left(\geq 39.5^{\circ} \mathrm{C}\right)$ & 2 \\
\hline \multirow{2}{*}{$\begin{array}{l}\text { mandibular } \\
\text { lymph node }\end{array}$} & normal & 0 \\
\hline & enlarged & 1 \\
\hline \multirow{3}{*}{ lung auscultation } & normal & 0 \\
\hline & moderately exacerbated (raw sounds) & 1 \\
\hline & $\begin{array}{l}\text { extremely exacerbated (rattle, } \\
\text { rhonchus) }\end{array}$ & 2 \\
\hline \multirow{3}{*}{$\begin{array}{l}\text { trachea } \\
\text { auscultation }\end{array}$} & normal & 0 \\
\hline & moderately exacerbated (raw sounds) & 1 \\
\hline & $\begin{array}{l}\text { extremely exacerbated (rattle, } \\
\text { rhonchus) }\end{array}$ & 2 \\
\hline \multicolumn{2}{|c|}{ maximum clinical score achievable } & 9 \\
\hline
\end{tabular}


used to perform statistical analyses of the data collected. The evaluation of all statistical analyses applied and, thus, the analysis of differences, was based on an error probability of $\mathrm{P}<0.05$. The data collected were examined for normal distribution using the Shapiro-Wilk test and as no normal distribution could be demonstrated, the median was calculated (25th/75th percentiles) and non-parametric tests were applied.

The Spearman correlation was used to determine whether the parameters SAA, abscess score, clinical score, age and the WBC were related to each other. Due to the relatively small number of samples regarding the differences in the distribution of SAA values within the two groups and febrile/ non-febrile foals, the data were analysed using the Fisher's exact test. The Wilcoxon Rank Sum Test was used to analyse the differences in SAA levels comparing the two groups and the febrile with the non-febrile foals. The Friedman test with a post hoc Sidak Test for multiple pair comparisons was used for the SAA values at each repeated measurement during therapy to provide a statement on developments during treatment. In addition, descriptive statistics and logistic regression were used to analyse the kinetics of SAA during treatment.

\section{Results}

Course of the disease in the participating study foals

None of the 52 foals showed a worsening of the lung findings after the initiation of treatment, and all foals recovered from pneumonia at the end of the treatment. One foal showed a new episode of pneumonia 96 days after initiation of first treatment (77 days after the end of the first treatment). The course of SAA concentration in that foal was similar to the first disease (Figure 1).

\section{SAA values at the day of diagnosis}

The foals with a moderate pneumonia (group 1, $n=31$ ) showed a SAA concentration of $367 \mathrm{mg} / \mathrm{L}$ (median; 25th/75th: 23-937; min: 4; max: 1296) and those with severe pneumonia (group 2, $\mathrm{n}=21$ ) a SAA concentration of $216 \mathrm{mg} / \mathrm{L}$ (median; 25th/75th: 16-690; min: 7; max: 1059). The SAA concentrations did not differ significantly between the two groups $(P=0.6)$ (Figure 2). By measuring the SAA (at an assumed cut-off value of $40 \mathrm{mg} / \mathrm{L}$ ), the value of foals with moderate pneumonia (group 1, $n=31$ ) was found to have increased in

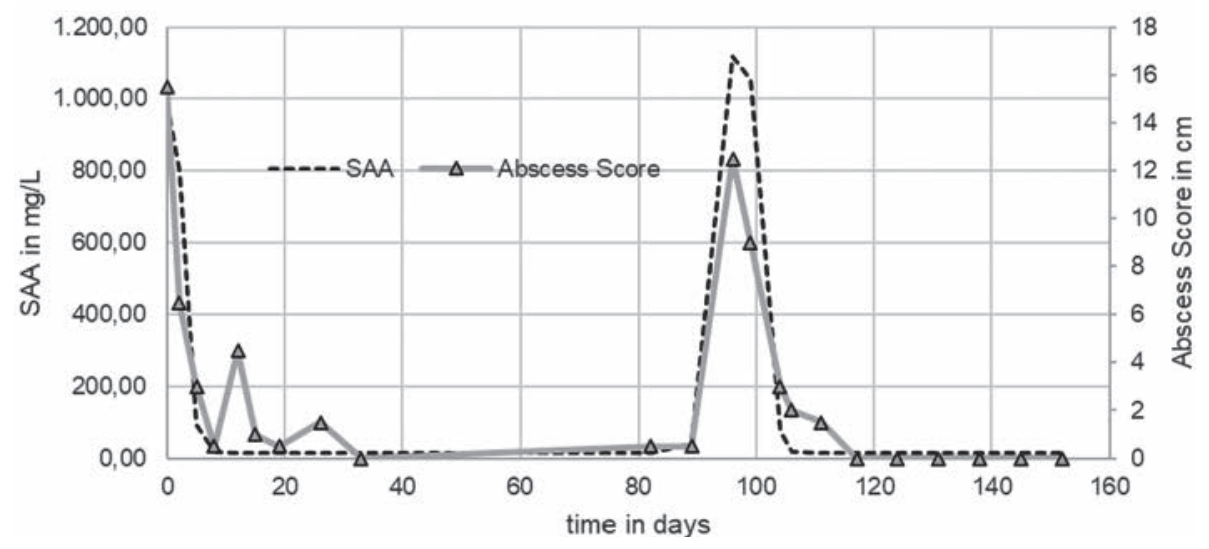

Fig. 1 Exemplary course of the abscess score and SAA concentration of the foal which suffered from another abscessing bronchopneumonia after the first moderate pneumonia. | Exemplarischer Verlauf des Abszess Scores und der SAA-Konzentration eines Fohlens, welches nach einer mittelgradigen Pneumonie erneut eine Pneumonie entwickelte.

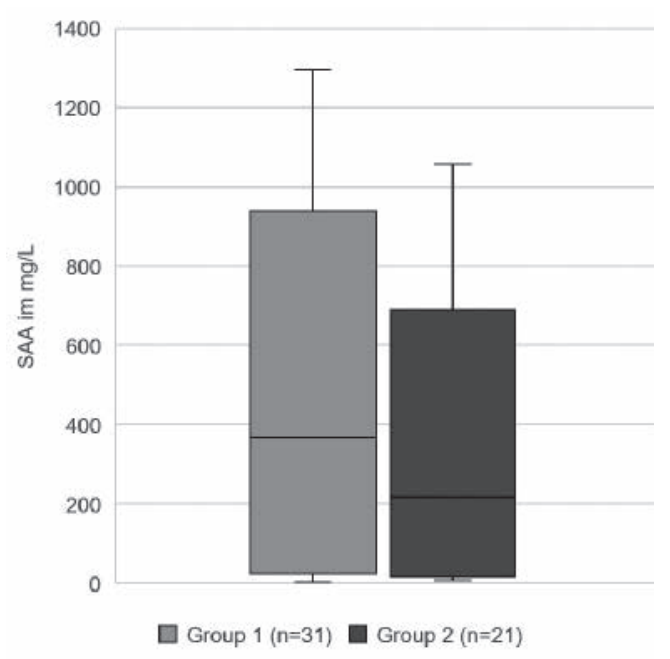

Fig. 2 SAA concentrations (reference range up to $40 \mathrm{mg} / \mathrm{L}$ ) of foals with moderate pneumonia (group $1, n=31$ ) and severe pneumonia (group 2, $\mathrm{n}=21$ ) on the day of diagnosis. | SAA-Konzentrationen (Referenzbereich bis zu $40 \mathrm{mg} / \mathrm{l}$ ) von Fohlen mit einer mittelgradigen Pneumonie (Gruppe 1, $n=31$ ) sowie hochgradigen Pneumonie (Gruppe 2, n=21) am Tag der Diagnose.

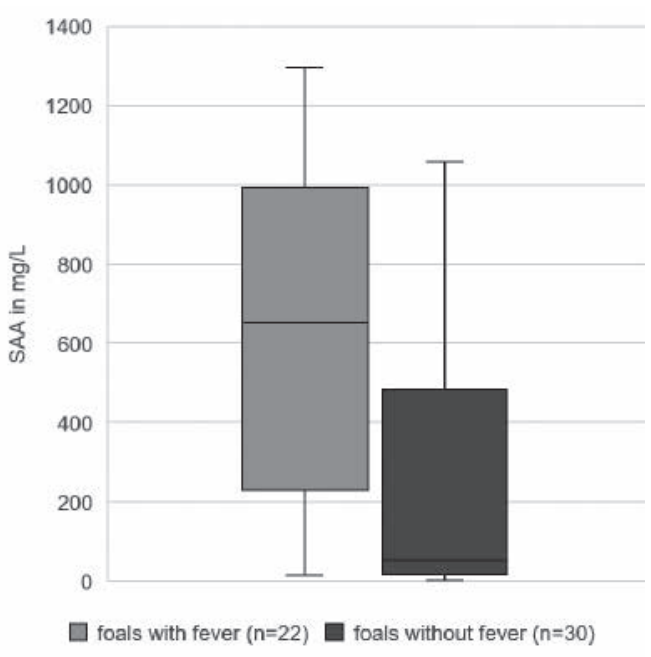

Fig. 3 SAA concentrations of foals with pneumonia and fever (body temperature $\geq 39.0^{\circ} \mathrm{C}, \mathrm{n}=22$ ) or with normal temperature (body temperature $<38.9^{\circ} \mathrm{C}, \mathrm{n}=30$ ) at diagnosis. | SAA-Konzentrationen von Fohlen mit Pneumonie und erhöhter Körpertemperatur ( $\geq 39,0^{\circ} \mathrm{C}, n=22$ ) oder physiologischer Körpertemperatur $\left(<38,9^{\circ} \mathrm{C}, \mathrm{n}=30\right)$ bei Diagnosestellung. 
$68 \%$ of cases, and in $71 \%$ of cases in foals with severe pneumonia (group 2, $\mathrm{n}=21$ ) (Table 2). There was no significant difference between moderately and severely ill foals $(P=1.0)$. Furthermore, the SAA values and the ultrasonographic scores, the clinical scores or the WBC counts did not correlate at the time of diagnosis.

Association between SAA values and fever on the day of diagnosis

Regardless of the severity of the pneumonia of these two groups, the SAA median was $652 \mathrm{mg} / \mathrm{L}$ (median; 25th/75th: 235-992; min: 15; max: 1296) in foals with a body temperature $\geq 39^{\circ} \mathrm{C}$ (fever, $n=22$ ) and significantly higher than in foals with body temperature $<38.9^{\circ} \mathrm{C}$ (without fever, $\mathrm{n}=30$ ) with $51 \mathrm{mg} / \mathrm{L}$ (median; 25th/75th: 16-452; min: 4; max: 1059) ( $\mathrm{P}=0.001)(\mathrm{Fi}-$ gure 3). Furthermore, if the foals initially had no fever, the SAA concentration on the day of diagnosis showed a level higher than $40 \mathrm{mg} / \mathrm{L}$ in $53 \%$ of cases. However, the SAA concentration was elevated in $91 \%$ of the cases in foals with fever (Table 3).

Kinetics of the SAA values during the treatment of pneumonia

The SAA values decreased significantly during the treatment in the group of foals with elevated SAA concentrations on the day of diagnosis $(n=36)$ (Figure 4A). The SAA concentrations in foals with moderate pneumonia (group 1, $\mathrm{n}=21$ ) on the day of diagnosis were significantly higher than in the following week and the week after. Furthermore, the values after three to four days were significantly lower than those measured after 1.5 weeks of treatment and the following measurements. The SAA values returned to the range of $<40 \mathrm{mg} / \mathrm{L}$ within five days (median; 25th/75th: 4-7).

When considering the foals with initially elevated SAA concentrations and severe pneumonia (group 2, $n=15$ ), the measured values decreased significantly after the day of diagnosis within three to four days. The SAA values decreased to values $<40 \mathrm{mg} / \mathrm{L}$ within four days (median; 25th/75th: 3-6). In addition, the SAA values and the duration of days in which the SAA concentrations returned to normal level correlated significantly (correlation coefficient $=0.56 ; P=0.0004$ ).

The normal SAA concentrations in foals $(n=16)$ which had a moderate or severe pneumonia stayed within normal limits during two weeks of duration of treatment (Figure 4C). One of these 16 patients (excluded of Figure 4C) with initially normal SAA values and a severe pneumonia showed a strong increase (to $733 \mathrm{mg} / \mathrm{L}$ ) of the SAA two days after the treatment was started (body temperature physiological and findings of further clinical examination remain constant) and, subsequently, a decrease with a comparable course to those foals

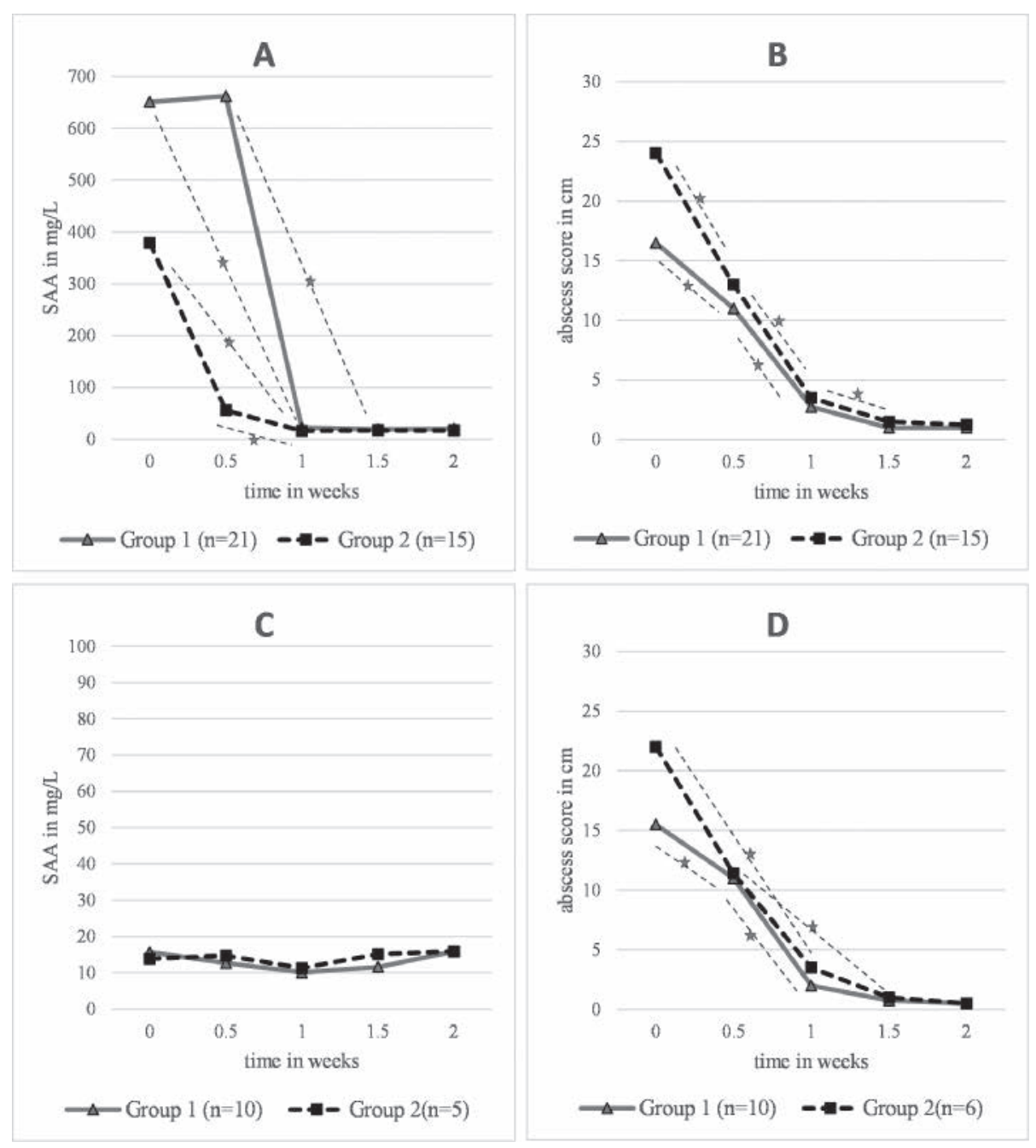

Fig. 4 Development of the SAA values (median) and abscess scores (median) during the first two weeks after the initiation of therapy of the foals with moderate pneumonia (group 1) and severe pneumonia (group 2). A: SAA values of foals $(n=36)$ with initially elevated SAA concentrations, B: abscess scores of foals $(n=36)$ with initially elevated SAA concentrations, C: SAA values of foals $(n=15)$ with initially normal SAA concentrations (SAA concentrations of a foal not included due to variations in the course of treatment), D: abscess scores of foals $(n=16)$ with initially normal SAA concentrations. Significant deviations are marked with $\star$. Entwicklung der SAA-Konzentrationen (Medianwerte) und des Abszess Scores (Medianwerte) innerhalb der ersten zwei Wochen nach Therapiebeginn der Fohlen mit mittelgradiger Pneumonie (Gruppe 1) und hochgradiger Pneumonie (Gruppe 2). A: SAA-Werte der Fohlen $(n=36)$ mit initial erhöhten SAA-Konzentrationen, B: Abszess Scores der Fohlen $(n=36)$ mit initial erhöhten SAA-Konzentrationen, C: SAA-Werte der Fohlen $(n=15)$ mit initial normaler SAA-Konzentrationen (SAA Konzentrationen eines Fohlens aufgrund von Schwankungen im Therapieverlauf nicht inkludiert), D: Abszess Scores der Fohlen $(n=16)$ mit initial normaler SAA-Konzentrationen. Signifikante Abweichungen sind mit $\star$ gekennzeichnet. 
with increased values. The other 15 foals did not show any elevated SAA values at any time during therapy.

\section{Association between SAA values and other parameters}

Foals with a moderate pneumonia (group 1, $\mathrm{n}=31$ ) showed a significant decrease of the abscess score during the first week after treatment was started. The ultrasound examinations of foals with elevated SAA concentrations $(n=21)$ on the day of diagnosis was without special findings after a duration of ten days (median; 25th/75th: 7-13 days).

In foals with a severe pneumonia (group 2, $n=21$ ), the significant decrease of the pulmonary lesions continued until 1.5 weeks of treatment (Figure 4B/D). The ultrasound examination of those foals with initially elevated SAA concentrations ( $n=15$ ) was without special findings 11 days (median; 25th/75th: 9-14 days) after the start of treatment.

The time from the normalisation of the SAA values until the normal ultrasonographic examination was three days (median; 25th/75th: 0-7 days) in foals with a moderate pneumonia (group 1, $\mathrm{n}=21$ ) and seven days (median; 25th/75th: 3-12 days) in foals with severe pneumonia (group $2, n=15$ ) (Table 4).

A correlation between the SAA concentrations and the abscess scores $(P<0.0001)$ was observed (correlation coefficient $=0.4$ ) in the course of therapy, and the SAA concentrations correlated moderately with the clinical scores $(P<0.0001$, correlation coefficient $=0.3)$. There was no cor-

Table 2 Foals with moderate pneumonia (group 1) and severe pneumonia (group 2) and their SAA concentrations (reference range up to $40 \mathrm{mg} / \mathrm{L}$ ) on the day of diagnosis of pneumonia. | SAA Konzentration (Referenzbereich bis zu $40 \mathrm{mg} / \mathrm{l}$ ) von Fohlen mit mittelgradiger Pneumonie (Gruppe 1) und und Fohlen mit hochgradiger Pneumonie (Gruppe 2) am Tag der Diagnosestellung Pneumonie.

\begin{tabular}{lccc} 
& $\begin{array}{c}\text { SAA } \\
<40 \mathrm{mg} / \mathrm{L}\end{array}$ & $\begin{array}{c}\text { SAA } \\
>40 \mathrm{mg} / \mathrm{L}\end{array}$ & Total \\
\hline $\begin{array}{l}\text { Foals with moderate } \\
\text { pneumonia } \\
\text { (group 1) }\end{array}$ & 10 & 21 & 31 \\
$\begin{array}{l}\text { Foals with severe } \\
\text { pneumonia } \\
\text { (group 2) }\end{array}$ & 6 & 15 & 21 \\
Total & 16 & 36 & 52 \\
\hline
\end{tabular}

Table 3 Number of foals with fever (body temperature $\geq 39.0^{\circ} \mathrm{C}$ ) and foals without fever (body temperature $<38.9^{\circ} \mathrm{C}$ ) and SAA value (reference range up to $40 \mathrm{mg} / \mathrm{L}$ ) on the day of diagnosis of pneumonia. | Anzahl der Fohlen mit Fieber (Körpertemperatur $\geq 39,0^{\circ} \mathrm{C}$ ) sowie Fohlen ohne Fieber (Körpertemperatur $<38,9^{\circ} \mathrm{C}$ ) und deren SAA-Konzentrationen (Referenzbereich bis $40 \mathrm{mg} / \mathrm{l}$ ) am Tag der Diagnose Pneumonie.

\begin{tabular}{lccc}
\hline & $\begin{array}{c}\text { SAA } \\
<40 \mathrm{mg} / \mathrm{L}\end{array}$ & $\begin{array}{c}\mathrm{SAA} \\
>40 \mathrm{mg} / \mathrm{L}\end{array}$ & Total \\
\hline body temperature $<38.9^{\circ} \mathrm{C}$ & 14 & 16 & 30 \\
body temperature $\geq 39.0^{\circ} \mathrm{C}$ & 2 & 20 & 22 \\
Total & 16 & 36 & 52 \\
\hline
\end{tabular}

relation between the WBC counts and SAA concentrations at the time of diagnosis or during treatment.

\section{Impact of the age of foals to the SAA concentration}

The initial SAA concentrations are significantly associated with the age of the foal at diagnosis of pneumonia ( $P=0.03$, correlation coefficient. $=-0.3)$; the younger foals have higher initial SAA concentrations. In addition, there is a moderate correlation $(P=0.007$, correlation coefficient $=-0.4)$ between the time until the SAA returned to the reference range and the age at diagnosis (Figure 5); the foals that showed no increased SAA values after less than one week $(n=27)$ were 118 days (median; 25th/75th: 111-125) old at the time of diagnosis; those whose values normalised after more than one week ( $n=9$ ) were 84 days (median; 25th/75th: 80-96) old; the foals whose SAA concentration normalises within one week were significantly older $(P=0.003)$.

Association between SAA concentration and the development of the pulmonary status

An ultrasound examination was considered as the gold standard for the evaluation of the lung status. The foals were considered to have a healthy lung if they showed no clinical signs of respiratory disorder and no pathologic ultrasonographic findings were detected. A total of 284 SAA samples were taken during treatment from the 36 foals whose SAA values were elevated at diagnosis of pneumonia. Of these 284 samples, 125 were taken from foals that still had ultrasonographically detectable pneumonia, of which 69 (55.2\%) had a SAA valve $>40 \mathrm{mg} / \mathrm{L}$ and 56 (44.8\%) were $<40 \mathrm{mg} / \mathrm{L}$. Only $7 / 159$ values $(4.4 \%)$ of 4 different ultrasonographically healthy foals were $>40 \mathrm{mg} / \mathrm{L}$ (Figure 6).

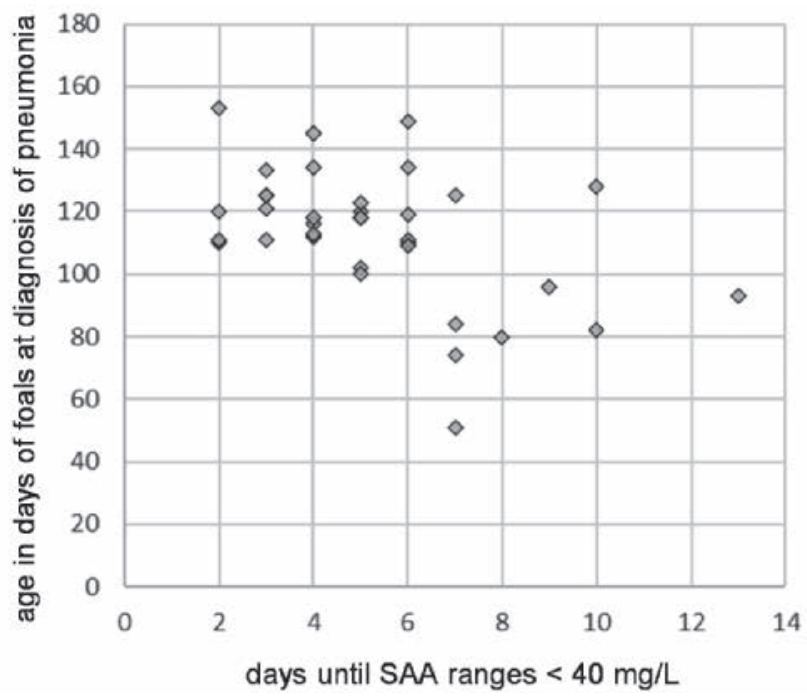

Fig. 5 Age (in days) of all 36 foals on the day of diagnosis of moderate or severe pneumonia and with an increased SAA concentration at diagnosis in relation to the number of days until their SAA concentration was normal (i.e. $<40 \mathrm{mg} / \mathrm{L}$ ). | Korrelation zwischen Alter (in Tagen) aller 36 Fohlen mit einer mittelgradigen oder hochgradigen Pneumonie und mit den erhöhten SAA-Konzentrationen zum Zeitpunkt der Diagnose und zur Daver in Tagen bis die SAA-Konzentration wieder $<40 \mathrm{mg} / \mathrm{l}$ (normal) gemessen worden ist. 


\section{Discussion}

The SAA with a response time of $6-12 \mathrm{~h}$ is a fast reacting and a sensitive marker for acute inflammatory processes. It can increase more than a hundredfold shortly after infection, which makes it an interesting parameter to diagnose pneumonia in foals (Hultén et al. 1999, Jacobsen et al. 2007, Thomé et al. 2018). In the current study, this SAA was measured in foals with moderate or severe pneumonia at the time point of diagnosis and during the treatment period in order to evaluate whether this parameter can help the veterinarian to evaluate the response to treatment.

The initial values were elevated ( $>40 \mathrm{mg} / \mathrm{L}$ ) in $67.7 \%$ of foals with moderate pneumonia (abscess score 15-19.5 cm, group $1, n=31$ ) and in $71.4 \%$ of foals with severe pneumonia (abscess score $>20 \mathrm{~cm}$, group 2, $\mathrm{n}=21$ ). A similar sensitivity of this parameter has also been observed in recent studies in foals with pneumonia, whereby the sensitivity at a threshold value of $64 \mathrm{mg} / \mathrm{L}$ is described in $64 \%$ (Giguère et al. 2016) or at a threshold value of $79 \mathrm{mg} / \mathrm{L}$ in $77 \%$ of foals (Thomé et al. 2018). Furthermore, in a previous study (Giguère et al. 2016), there was no significant correlation between the severity of the pneumonia and the SAA concentration; this was also demonstrated in this study. These results show clearly that SAA is not reliable as a single diagnostic tool for detecting pneumonia (Cohen et al. 2005, Passamonti et al. 2015).

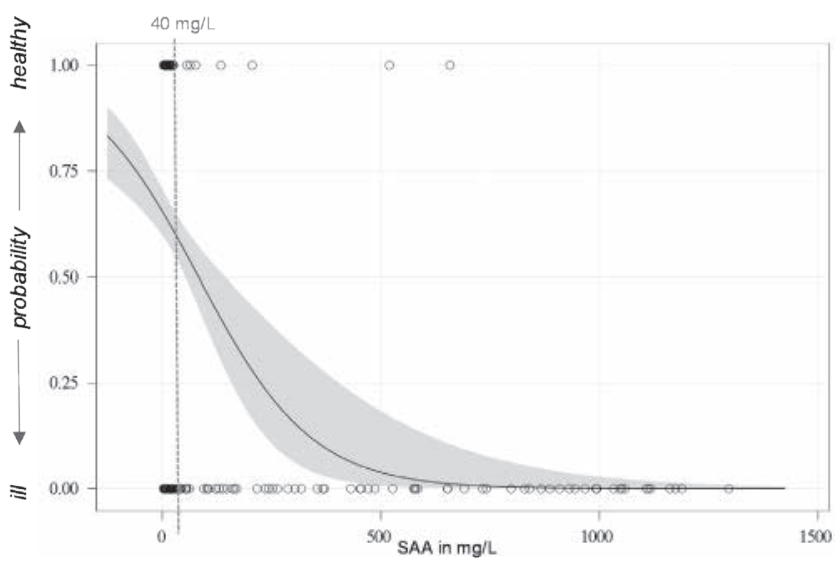

Fig. 6 Ratio of SAA level to disease state (healthy / ill) as a logistic regression of all 284 individual measurements of 52 foals. | Verhältnis von SAA-Konzentration zu Krankheitszustand (gesund / krank) als logistische Regression aller 284 Einzelmessungen der 52 Fohlen.
In the current study, the diagnostic value of the SAA was better in the foals which were presented with fever (22/52) and, thus, the pneumonia was no longer in the subclinical stage. Of these cases, 20 foals (91\%) showed initially elevated SAA values and only two foals (9\%) had a normal SAA. Furthermore, the SAA values of the foals with fever were significantly higher ( $P=.0013$ ) with $652 \mathrm{mg} / \mathrm{L}$ (median; 25th/75th: 235992) than those of the foals without fever with $51 \mathrm{mg} / \mathrm{L}$ (median; 25th/75th: 16-452). Therefore, SAA turns out to be a good diagnostic tool in cases of abscessing bronchopneumonia in foals with fever.

Since the half-life of SAA is short (30-120 min) (Hoffman and Benditt 1983, Uhlar and Whitehead 1999), the question arises how this very sensitive APP behaves during the treatment period in foals with abscessing bronchopneumonia. A low correlation between the SAA concentrations and the abscess scores was observed during the treatment period. While the SAA levels had already normalised within the first week in most of the foals $(27 / 36)$, the ultrasonographic examinations were unremarkable during the second week of treatment (32/36). Due to the weak correlation between the days until the SAA had regressed and the level of the initial SAA, it must be assumed that the more pronounced the initial inflammation reaction, the longer the body needs to cope with it. The rapid decrease in the SAA level does not seem to occur simultaneously with the healing of the lesions in the lung tissue; it takes more time for affected areas in pulmonary tissue to recover than the acute inflammatory phase, according to the SAA values. In a recent study, five out of six foals with successfully treated $R$. equi-pneumonia were also measured for diagnostic high SAA values; the values decreased after two weeks of therapy to a normal range (Giguère et al. 2016). If there is no reduction in SAA levels after the initiation of therapy, further follow-up examinations should be made in order to detect or exclude possible therapy failure at an early stage (Prato et al. 2012).

Another aspect of this study was to determine the diagnostic value of the SAA in foals with abscessing pneumonia to monitor the response to treatment and the clinical condition. In a further study, the SAA concentrations were measured in nine adult horses with bacterial pneumonia and proved to be a useful tool for monitoring the clinical condition of those patients (Hobo et al. 2007). The current study showed a correlation between the clinical score and the SAA value in the course of the treatment of foals with pneumonia. Thus, this APP is a helpful parameter to assess the clinical condition of foals during the treatment period of pneumonia.

Table 4 Time (in days) from the diagnosis to normalisation of the SAA concentrations and normal ultrasonographic scores of foal's lung, and the time interval between these two events in foals with moderate (group 1) or severe (group 2) pneumonia and initially elevated SAA concentrations.

Zeit (in Tagen) von der Diagnosestellung bis zur Normalisierung der SAA-Konzentration und der ultrasonographischen Scores der Lunge der Fohlen sowie das Zeitintervall zwischen diesen beiden Ereignissen bei Fohlen mit mittelgradiger (Gruppe 1) und hochgradiger (Gruppe 2) Pneumonie, deren SAA-Konzentrationen initial erhöht waren.

$\begin{array}{cr}\text { group } 1(n=21) & \text { group } 2(n=15) \\ \text { median }(25 \text { th-75th }) & \text { median }(25 \text { th }-75 \text { th })\end{array}$

number of days from diagnosis to the time point which the SAA concentrations were $<40 \mathrm{mg} / \mathrm{L}$

$$
5(4-7)
$$

$4(3-6)$

number of days from day of diagnosis to the time point which the ultrasonographic scores of the lungs were normal

time interval in days between the above events
$10(7-13)$
$11(9-14)$ 
Since SAA is a non-specific inflammatory marker, the cause of an increase may also be another extrapulmonary disorder (Giguère et al. 2016). This explains why four foals with no more sonographical pulmonary findings had increased SAA values at a total of seven blood sample times. Foals with increased SAA values still showed ultrasonographically detectable pulmonary consolidations in all further measurements $(95.6 \%)$ during the course of treatment. Thus, if SAA values are initially elevated, lung disease can still be assumed if the following SAA measurements remain increased. Since the SAA value decreases more rapidly than the reference range compared to the abscess score, it is also possible that foals are recovering but not yet sound. This suggests that the prognostic value of the $S A A<40 \mathrm{mg} / \mathrm{L}$ is only of limited use.

Another APP, CRP was shown to be useful to determine the treatment duration in dogs suffering from bronchopneumonia. The dogs were treated for five to seven days beyond normalisation of the major APP CRP and recovered to 100\% (Viitanen et al. 2017). The SAA is also described as a useful parameter in pneumonia in dogs (Christensen et al. 2014). The decision of the end of treatment based on the CRP led to significantly shorter treatment durations without increasing the risk of a relapse compared to standardized treatment protocols based on radiographic changes (Viitanen et al. 2017). The results of the current study of foals with bronchopneumonia show that the SAA value during the first week of treatment allows one to estimate the response to therapy and whether the treatment can be terminated a few days later. Nonetheless, the final decision to terminate the treatment should always be based on clinical and sonographical examination since the SAA values and the abscess score do not correlate well after one week of treatment and later.

Additionally, young foals (below seven days of age) should be evaluated with even more care than older foals with pneumonia. Younger foals are also generally more susceptible to R. equi pneumonia, as shown in previous studies (Giguère et al. $2011 \mathrm{~b}$ ). The older the foal, the sooner it is able to eliminate the infection (Venner et al. 2012) and, accordingly, the inflammatory reaction in the body is less or absent, which is reflected in the level of SAA values. The age of the foals in the current study correlates with the SAA concentration and with the time in days, until the value reaches the reference range again. Accordingly, older foals are more able to clear the infection and this is reflected in initially lower and faster decreasing SAA values.

\section{Conclusion}

The SAA as a single diagnostic parameter for pneumonia has again not proven itself due to low sensitivity. The probability of increased SAA values at diagnosis in foals with clinical signs of pneumonia is high. Furthermore, the SAA concentration can reflect the clinical condition of a foal during the treatment of pneumonia in patients with an elevated SAA concentration at diagnosis. Since the SAA concentration decreases to normal values before the lung is free of ultrasonographic pathologic findings, the SAA might help to monitor the course of treatment and estimate the adequate time to finish the treatment. Nevertheless, the most reliable method is still the ultrasonographic examination of the lung, and the SAA can only be used as an additional parameter for the evaluation of treatment.

\section{References}

Belgrave R. L., Dickey M. M., Arheart K. L., Cray C. (2013) Assessment of serum amyloid $A$ testing of horses and its clinical application in a specialized equine practice. J. Am. Vet. Med. Assoc. 243 (1), 113-119; DOI 10.2460/javma.243.1.113

Christensen M. B., Langhorn R., Goddard A., Andreasen E. B., Moldal E., Tvarijonaviciute A., Kirpensteijn J., Jakobsen S., Persson F., Kjelgaard-Hansen M. (2014) Comparison of serum amyloid $A$ and C-reactive protein as diagnostic markers of systemic inflammation in dogs. Can. Vet. J. 55, 161-168

Cohen N. D., Chaffin M. K., Vandenplas M. L., Edwards R. F., Nevill M., Moore J. N., Martens R. J. (2005). Study of serum amyloid A concentrations as a means of achieving early diagnosis of Rhodococcus equi pneumonia. Equine Vet. J. 37 (5), 212-216; DOI 10.2746/0425164054530704

Giguère S., Berghaus L. J., Miller C. D. (2016) Clinical assessment of a point-of-care serum amyloid $A$ assay in foals with bronchopneumonia. J. Vet. Intern. Med. 30 (4), 1338-1343; DOI 10.1111/ jvim. 13978

Giguère S., Cohen N. D., Chaffin M. K., Hines S. A., Hondalus M. K., Prescott J., Solvis N. M. (2011a) Rhodococcus equi: clinical manifestations, virulence and immunity. J. Vet. Intern. Med. 25, 1221-1230; DOI 10.1111/j.1939-1676.2011.00804.x

Giguère S., Cohen N. D., Chaffin M. K., Solvis N. M., Hondalus M. K., Hines S. A., Prescott J. (2011 b) Diagnosis, treatment, control, and prevention of infections caused by Rhodococcus equi in foals. J. Vet. Intern. Med. 25, 1209-1220; DOI 10.1111/j.1939. 1676.2011.00835.x

Giguère S., Hernandez J., Gaskin J., Miller C., Bowman J. L. (2003) Evaluation of white blood cell concentration, plasma fibrinogen concentration, and an agar gel immunodiffusion test for early identification of foals with Rhodococcus equi pneumonia. J. Am. Vet. Med. Assoc. 222, 775-781

Giguère S., Prescott J. F. (1997) Clinical manifestations, diagnosis, treatment, and prevention of Rhodococcus equi infections in foals. Vet. Microbiol. 56, 313-334; DOI 10.1016/s0378$1135(97) 00099-0$

Hagist C. (2016) Genotyping of Rhodococcus equi strains from Germany, isolated in foals and other animal species. Thesis, Veterinary School of Hanover

Hennig M. (2020 in print) Detection of Rhodococcus equi in tracheobronchial secretion and faeces of foals with pneumonia. Thesis, Veterinary School of Hanover

Heyers P. (2005) Comparison of the detection of Rhodococcus equi by microbiological culture with the detection by polymerase chain reaction in endoscopically extracted tracheobronchial secretion in foals. Thesis, Veterinary School of Hanover

Hobo S., Niwa H., Anzai T. (2007) Evaluation of serum amyloid A and surfactant protein $D$ in sera for identification of the clinical condition of horses with bacterial pneumonia. J. Vet. Med. Sci. 69 (8), 827-830; DOI 10.1292/jvms.69.827

Hoffman J. S., Benditt E. P. (1983) Plasma clearance kinetics of the amyloid-related high density lipoprotein apoprotein, serum amyloid protein (ApoSAA), in the mouse. J. Clin. Invest. 71, 926-934; DOI 10.1172/JCI1 10847

Hoffmann A. M., Viel L., Prescott J. F. (1993) Microbiologic changes during antimicrobial treatment and rate of relapse of distal respiratory tract infections in foals. Am. J. Vet. Res. 54, 1608-1614

Hultén C., Demmers S. (2002) Serum amyloid A (SAA) as an aid in the management of infectious disease in the foal: comparison with total leucocyte count, neutrophil count and fibrinogen. Equine Vet. J. 34 (7), 693-698; DOI 10.2746/042516402776250360 
Hultén C., Tulamo R. M., Suominen M. M., Burvall K., Marhaug G., Forsberg M. (1999) A non-competitive chemiluminescence enzyme immunoassay for the equine acute phase protein serum amyloid A (SAA) - a clinically useful inflammatory marker in the horse. Vet. Immunol. Immunopathol. 68 (2-4), 267-281; DOI 10.1016/ s0165-2427(99)00027-6

Jacobsen S., Andersen P. (2007) The acute phase protein serum amyloid $A(S A A)$ as a marker of inflammation in horses. Equine Vet. Educ. 1, 38-46; DOI 10.2746/095777307X177235

Lämmer M. (2010) Detection of Rhodococcus equi in faeces and tracheobronchial secretions of foals on a farm with endemic rhodococcosis: comparison of healthy foals and foals with pulmonary abscesses. Thesis, Veterinary School of Hanover

Lavoie J. P., Fiset L., Laverty S. (1994) Review of 40 cases of lung abscesses in foals and adult horses. Equine Vet. J. 26, 348-352; DOI 10.1111/i.2042-3306.1994.tb04401.x

Passamonti F., Vardi D. M., Stefanetti V., Marenzoni M. L., Prato S., Cévese P., Coletti M., Pepe M., Casagrande Proietti P., Olea-Popelka F. (2015) Rhodococcus equi pneumonia in foals: an assessment of the early diagnostic value of serum amyloid A and plasma fibrinogen concentrations in equine clinical practice. Vet. J. 203 (2), 211-218; DOI 10.1016/i.tvil.2014.08.033

Prato S., Passamonti F., Tamantini C., Cercone M., Nannarone S., Bazzica C., Gialletti R., Maggio C., Cerasoli I., Di Meo A., Pepe M. (2012) Serum amyloid A, fibrinogen, and haptoglobin as inflammation markers in the horse: preliminary results. Vet. Sci. 125-128
Satué K., Calvo A., Gardón J. C. (2013) Factors influencing serum amyloid type A (SAA) concentrations in horses. Open J. Vet. Med. 3, 58-66; DOI 10.4236/ojvm.2013.31010

Slovis N. M., McCracken J. L., Mundy G. (2005) How to use thoracic ultrasound to screen foals for Rhodococcus equi at affected farms. Proc. Am. Assoc. Equine Practnrs. 51, 274-278

Thomé R., Weber C., Rohn K., Venner M. (2018) Serum amyloid A concentration in foals - Can it help when making a treatment decision in foals with pneumonia? Pferdeheilkunde 34 (1), 61-67; DOI 10.21836/pem20180111

Uhlar C. M., Whitehead A. S. (1999) Serum amyloid A, the major vertebrate acute-phase reactant. Eur. J. Biochem. 265, 501-523 DOI: 10.1046/j.1432-1327.1999.00657.x

Venner M., Meyer-Hamme B., Verspohl J., Hatori F., Shimizu N., Sasaki Y., Kakuda T., Tsubaki S., Takai S. (2007) Genotypic characterization of VapA positive Rhodococcus equi in foals with pulmonary affection and their soil environment on a warmblood horse breeding farm in Germany. Res. Vet. Sci. 83, 311-317; DOI 10.1016/j.rvsc.2007.01.009

Venner M., Rödiger A., Lämmer M., Giguère S. (2012) Failure of antimicrobial therapy to accelerate spontaneous healing of subclinical pulmonary abscesses on a farm with endemic infections caused by Rhodococcus equi. Vet. J. 192, 293-298; DOI 10.1016/i. tvjl.201 1.07.004

Viitanen S. J., Lappalainen A. K., Christensen M. B., Sankari S., Rajamaki M. M. (2017) The utility of acute-phase proteins in the assessment of treatment response in dogs with bacterial pneumonia. J. Vet. Intern. Med. 31 (1), 124-133; DOI 10.1111/jvim.14631 